\title{
HOW STOCHASTIC COST ESTIMATES COULD BE APPLIED IN RELATION TO TARGET VALUE DESIGN
}

\author{
Olav Torp ${ }^{1}$
}

\begin{abstract}
Approaches like Target Value Design (TVD) has gained more and more attention in the Construction Industry. Critical issues with these principles are how the cost targets are set, how shared profit is agreed upon and made transparent, and how production costs are steered towards the target costs and tracked. Research has shown positive applications of TVD, but also remaining challenges with the approach. This paper will focus on the process of setting the cost targets in TVD. In traditional design processes, the costs are estimated based on the finalized design. In TVD, design and construction is steered towards the constraints, while maximizing the value for the costumer. Based on the client value, Allowable Cost are set. In Scandinavian countries, stochastic cost estimation methods have been applied to estimate project costs and to set cost targets for projects over many years. The cost targets are set prior to detail design. The purpose of this paper is to discuss how stochastic estimates could be applied in TVD. The method used is a literature review, in combination with a case study of cost estimation principles in two Norwegian public agencies. Findings show that stochastic cost estimates could be used both as input to set Allowable Cost and to estimate the Market Cost.
\end{abstract}

\section{KEYWORDS}

Target value design, target costing, stochastic cost estimation, cost target

\section{INTRODUCTION}

Target Value Design (TVD) has gained increased attention in the construction industry over the latest years. Successful application of TVD in construction has been reported (e. g. Ballard and Reiser 2004; Ballard and Pennanen 2013; Tillmann et al. 2017). Still, it seems like the application of TVD with the support of Integrated Project Delivery (IPD) principles some projects struggle to meet their target costs (Tillmann et al. 2017).

Tillmann et al. (2017) report that factors that influence the ability to deliver a project to target costs are 1) how cost targets are set and market price is estimated, 2) how shared profit is agreed upon and made transparent and 3) how production costs are steered towards

\footnotetext{
1 Associate Professor, Norwegian University of Science and Technology, Trondheim, Norway, +47 934226 73, olav.torp@ntnu.no.
} 
the target cost and tracked, so risks can be identified and mitigated. This paper focus on the first aspect mentioned above, more specifically challenges related to how to set the cost targets and estimate market price in Target Value Design.

All cost estimates and targets are forecasts and uncertain numbers. Particular cost models are developed to address variability and uncertainty, e.g. stochastic cost estimation methods (Nguyen et al. 2008; Lichtenberg 2000). In the Scandinavian countries, stochastic cost estimation methods are widely used to estimate project cost and as a basis for setting cost targets. The purpose of this paper is to discuss how to apply stochastic estimates in TVD. To achieve the purpose of the paper, we address the following research questions:

1. How are cost targets set in TVD?

2. How are cost targets set with stochastic cost estimates?

3. How can stochastic cost estimates contribute to TVD?

\section{RESEARCH METHOD}

To address the research questions, a literature review and a case study was performed. The literature review aimed for a general overview of the literature on Target Value Design, and was applied to answer the first research question. The case study aimed to answer the second research question. To answer the last research question, results from the literature review and from the case study were used to discuss opportunities to use stochastic estimates in TVD.

The literature review was performed by searching for literature in databases like the university database Oria, Google Scholar and at iglc.net to find previous IGLC-conference papers. Search words like Target Costing, Target Value Design and Target Value Delivery were used. Search on Target Costing resulted in over 1000 hits in Google Scholar and 300 in Oria, most of them related to manufacturing and industry. Search for Target Value Design resulted in around 100 hits in Google Scholar and around 50 in Oria. Some relevant articles were picked based on these searches. Search for Target Value Delivery gave 16 hits in Google Scholar and 5 hits in Oria, all relevant. The literature was scanned and relevant sources were analysed for content on how targets are set and applied in TVD.

The case study approach proved a sound research method for studying how cost targets are set in two Norwegian public agencies. The method contributes to extending our knowledge and understanding about the phenomena, and is according to Yin (2014), a preferred method for answering 'how' research questions. The public agencies Norwegian Public Roads Authority and Statsbygg, the Norwegian public builder and building owner, were chosen based on their extensive experience with stochastic cost estimates. The case study was performed by document study of internal routines for cost estimation and cost management. This provided a convenient source of insight into the particular phenomena studied (Fellows et al. 2015). Furthermore, the use of documents provided some essential advantages as a mean of collecting data, as documents are non-reactive and a stable source of data, i.e., unaffected by the research process (Bowen, G.A 2009). 


\section{TARGET VALUE DESIGN, CONCEPTUAL COST ESTIMATES AND SETTING TARGETS}

Target Value Design (TVD) is a management practice in which the design and construction are steered towards the project constraints while maximizing customer value (Ballard, 2011). TVD was adopted from Target Costing (TC), a management practice that has been widely used in the new product development and manufacturing industries to ensure predictable profit planning (Cooper and Slagmulder, 1997; Feil, Yook and Kim, 2004). In Target Costing, the cost is an input in the design stage rather than an output of it (Do et al. 2015). In Target Value Design, the customer Value, rather than the costs, serves as input to set the cost targets. Target Value Design focus on setting targets, design to targets and build to targets (Zimina et al. 2012).

TVD is based on conceptual cost estimates prior to design, based on programmatic data (Ballard and Pennanen 2013). Programmatic data includes what is wanted (functionalities, capacities, and features of the desired asset), where the asset is to be located and when it is to be produced. The Allowable Cost is cost the costumer finds acceptable; i.e., they are willing and able to pay that amount and are assured that they will receive in return what they want. The costumer set Allowable Cost. The Market Cost is output from the cost model and estimated by the project team. Uncertainties related to market fluctuations and how escalations will play over the years seems to be the first challenge for teams implementing TVD (Tillmann et al. 2017). Pennanen and Ballard (2008) developed the following process steps for setting the target costs.

1. Assess the business case

2. Determine stakeholder values and define specifications of the project

3. Determine the Allowable Cost

4. Determine the Expected Cost

5. If Expected Cost is bigger than Allowable Cost then modify the specifications

6. Go to Step 3

7. When Expected Cost is equal to or less than the Allowable Cost, start project delivery by setting a target cost equal to or below Expected Cost.

8. Launch design phase

9. Decompose product level target cost to component level target cost

\section{CONCEPTUAL COST ESTIMATION IN TVD}

In Target Costing, the cost is to be estimated directly from the client's requirements rather than from designs offered to satisfy those requirements (Pennanen and Ballard 2008). Pennanen and Ballard (2008) present a method of determining Expected Cost from client requirements. Performance, specifications and target cost should be defined before conceptual design (Tanaka, M. 1989). Two cost perspectives can be used to determine target cost in construction (Ballard 2006 and Ballard 2007):

1. The customer defines Allowable Cost. It is a cost that the customer is willing and able to pay for a facility with defined performance. The project business plan should specify Allowable Cost. 
2. The project team defines the Expected Cost. It would be the cost if the facility with determined performance were provided at current best practice.

\section{STOCHASTIC COST ESTIMATES}

Nguyen et al. (2008) discuss different types of cost models, from parametric cost estimates to unit price estimates, based on resources and operations. Cost estimates are forecast of cost and they are always uncertain. Given the uncertainty and structural complexity, the use of deterministic historical cost database to estimate the cost of construction is not justifiable (Nguyen et al. 2008). Love et al. (2015) state that a base estimate (deterministic) plus the contingency figure typically form a project's estimated costs. Contingency can be defined as "the amount of funds, budget, or time needed above the estimate to reduce the risk of overruns of project objectives to a level acceptable for the organization" (PMI 2011).

Particular cost models are developed to deal with variability and uncertainty, like stochastic cost estimation methods (Nguyen et al. 2008; Lichtenberg 2000). Fortune and Cox (2005) found that these new models were not widely used in the UK. These kinds of approaches are commonly used in infrastructure projects in the Nordic countries, especially stochastic cost estimation methods (Lichtenberg 2000; Torp and Klakegg 2016; Klakegg and Lichtenberg 2016). Stochastic methods are used for decades to estimate project cost, mostly in the front-end of projects (Lichtenberg 2000; Klakegg and Lichtenberg 2016; Torp and Klakegg 2016), but also in the design phase and after design to calculate the cost for the chosen design prior to construction. Lichtenberg (2000) introduced the successive principle, saying that when estimating cost for projects, one should use a top-down approach, include everything, focus on uncertainty and use subjective estimation. Torp and Klakegg (2016) show this approach applied for estimating the costs of demolition and decommissioning of a Nuclear Power Plant. Torp and Klakegg (2016) discuss some challenges with the approach, and how to overcome some of the challenges. The main challenges seem to be the composition of the estimation team, the level of detail in the estimation model, lack of focus on opportunities, underestimation of uncertainty and underestimation of the Expected cost.

Stochastic cost estimates are presented as an Expected Cost (mean value) for the facility with the variability given as standard deviation (Lichtenberg 2000). The results are presented in a probability distribution for the total cost for the facility, as shown in Figure 1 (Johansen et al. 2014). Based on the probability distribution of the total project cost, the client could set the cost limit at a chosen level of probability. Figure 1 shows an example of a probability distribution. Often the probability distribution could be represented by a normal distribution. Then Expected Cost is at the probability level of $50 \%$, meaning that it is $50 \%$ probability of ending up below Expected Cost. The size of the standard deviation decides the steepness of the probability distribution. Cost targets could be set at a higher probability level than $50 \%$. The Norwegian Ministry of Finance have decided that the upper cost frame, defined as the budget, for large Norwegian investment projects should be set at $85 \%$ probability, meaning that it is $85 \%$ probability of keeping to budget (Lichtenberg 2016), defined as C in Figure 1. 


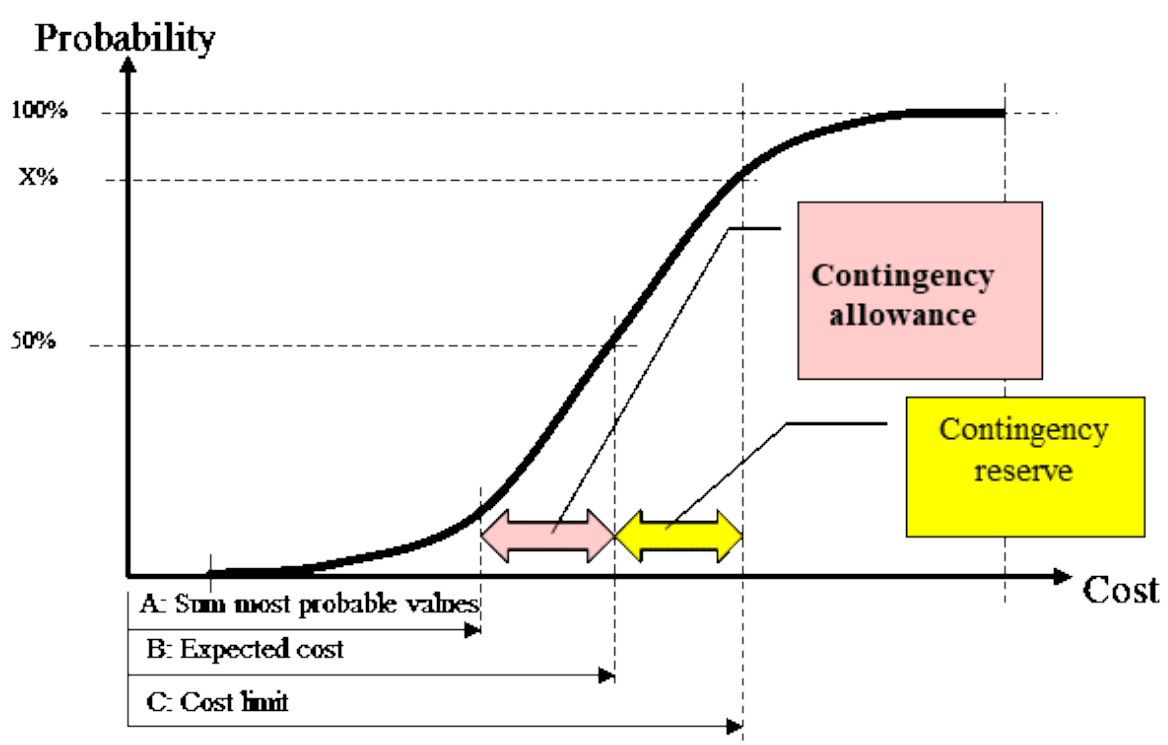

Figure 1. Probability distribution of the cost estimate for a project (Johansen et al. 2014).

\section{HOW TO SET TARGETS WITH STOCHASTIC METHODS}

The Public sector in Norway has applied stochastic methods to estimate costs and to set the cost targets for many years. The Norwegian Ministry of Finance has developed a guideline on how to do cost estimation for large public Norwegian investment projects (Norwegian Ministry of Finance 2008). The guideline states that a deterministic cost estimate should be followed by an uncertainty analysis, including a stochastic cost estimate (Norwegian Ministry of Finance 2008). The guideline is applied in most large Norwegian public construction projects, like building, road and railway projects. The cost targets include a cost limit, or the upper-cost frame which should be set at a probability level of $85 \%$, also called P85. This means that when setting the cost limit, it should be $85 \%$ probability for the project having enough money.

The Norwegian Public Roads Administration (NPRA) use stochastic cost estimation methods (NPRA, 2015). NPRA has developed a cost estimation model and guidelines on how to set cost targets (NPRA 2018). Before the final decision to start the project, the cost limit is set at P85, according to the rules from Ministry of Finance. NPRA get P50 as their cost target. In addition, a steering goal for the project manager is set at probability level of $45 \%$, being the project manager's cost target. NPRA has traditionally not used Target Costing or Target Value Design principles. However, a new system implemented, applying a change log from the front end all through the project, together with defined cost targets will increase focus on cost estimation and control, and drive them towards thinking like TVD. In the front-end, cost-benefit analyses are performed to decide whether the project is profitable or not, and at what cost it is profitable.

Statsbygg is the Norwegian government's principal advisor in construction and property affairs, building commissioner, property manager, and property developer. Statsbygg is a public sector administration company responsible to the Ministry of Local Government and Modernisation (KMD). Statsbygg provides appropriate, functional premises to public 
sector enterprises, as well as realising principal socio-political objectives concerning architecture, governmental planning interests, preservation of heritage sites and the environment. In some cases, Statsbygg acts as a builder during the planning and construction, and then the building is transferred to a public organization who will own and facilitate the building. In other cases, Statsbygg also owns and facilitate the building for the lifetime. The building is then leased to public sector users. In these cases, Statsbygg has applied principles similar to TVD for years, where the value is set prior to design, based on an agreement on level of the tenancy, and the tenancy is used as a constraint for the design and construction. For other types of buildings, Statsbygg has not applied principles like TVD.

The Ministry of Local government and Modernisation developed a guideline for frontend management of large public building projects (KMD 2017mainly to improve cost control. The guideline applies to building projects in Statsbygg and states that Design to Cost principles should be used, followed by implementation of a change log. This is similar to the new rules for NPRA. The end of the pre-project stage should be followed by a decision by the Government about a steering goal and cost limit for the project. The cost limit is decided to be at the level of P85, while the steering target for the project management is at the level of Expected Cost.

Lichtenberg (2016) shows results from 40 Danish road construction projects using stochastic cost estimates. The results shows that far more projects were under the Expected Cost compared to those that exceeded it. The average savings related to Expected Cost were approximately $5 \%$. Data from 78 large Norwegian public investment projects applying stochastic estimates, mainly road, building and railway projects but also including some ICT projects shows that around $50 \%$ of the projects end up below Expected Cost and around $80 \%$ end up below upper cost frame (Welde 2017). The total budget of the 78 projects is NOK 124.5 billion. The total final costs is NOK 117 billion. In other words, the portfolio of projects turned out to be NOK 7.5 billion (6\%) cheaper than budgeted. These results prove superior to what is documented in similar international studies. Morris and Hough (1987) show cost overruns on from 40 - $200 \%$. Flyvbjerg et al. (2002) show average cost overruns on $28 \%$, based on a study of 258 road and railway projects.

\section{DISCUSSION - HOW CAN STOCHASTIC COST ESTIMATES CONTRIBUTE TO TVD?}

This section will adress research question 3 , how stochastic cost estimates could contribute to TVD. The basis for this discussion is the literature review and the case studies.

Not much literature was identified on how cost targets are set in TVD. Pennanen and Ballard (2008) present a model designed to set targets, based on a building information cost model. The model was developed to support a dialogue between Allowable Cost and Expected Cost, though it is not very specific on how the cost targets are set in TVD. The costumer should define Allowable Cost, what he is willing and able to pay. The project team should estimate the Market Cost, as Expected Market Cost. Target cost should be set below Expected Cost. 
With stochastic estimates, Expected Cost and standard deviation are calculated, constituting the basis for the probability distribution of the total costs. Cost targets are set from the probability distribution, including contingency to reduce the risk of overruns of project objectives to a level acceptable for the organization. Both the NPRA and Statsbygg set their cost targets prior to design based on stochastic cost estimates. The Norwegian Ministry of Finance has decided that the cost limit should be set at a probability level of $85 \%$. This will then define the Allowable Cost for these projects. With this situation, it is a $15 \%$ probability of ending up above Allowable Cost. Cost target for the project manager will be set at Expected Cost, or $50 \%$ probability level when the probability distribution is given as a normal distribution. It is then important to steer both the design and construction to targets (Ballard et al. 2015). TVD is not widely used in the Norwegian public sector.

In TVD, the costumer should set Allowable Cost. Allowable Cost should be set based on the value of the facility for the customer, and what the customer is willing to pay, based on what the customer gets in return (Ballard and Pennanen 2013). The aim is to define the value of the facility, and financial constraints. The customer must decide what he is able and willing to pay to get this value (Zimina et al. 2012). Statsbygg applies this thinking in projects where they are responsible for construction and maintenance, and where they own the facility. Then the users pay yearly tenancy to use the facility. Stochastic estimates could be applied to estimate and set the value. The value could be considered as an uncertain number, and could by stochastic approach be represented by a probability distribution, see Figure 2.

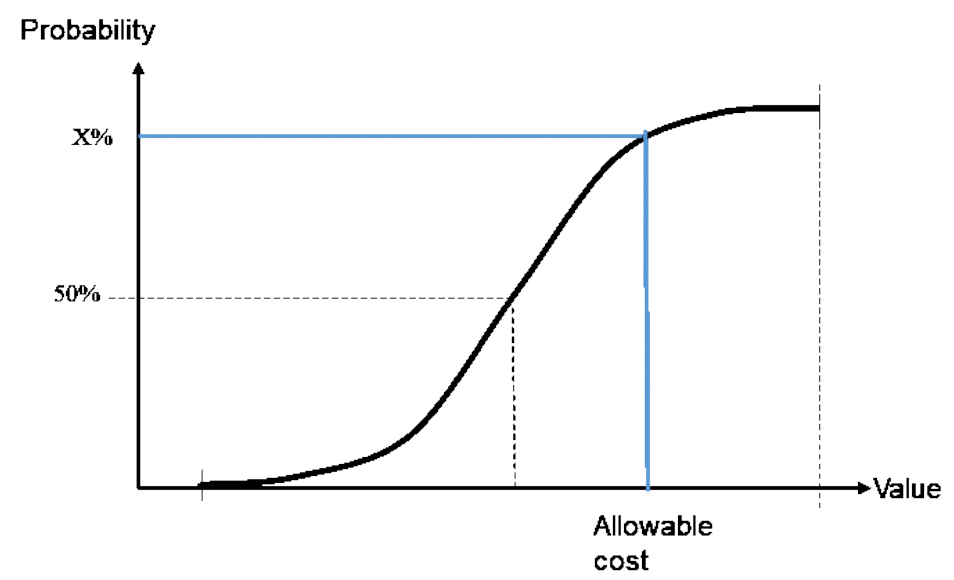

Figure 2. Probability distribution of the value, used to set Allowable cost.

Setting Allowable Cost from the estimates of value of the facility, you would be interested in knowing how likely it is that you manage to create the intended value within the Allowable Cost. Choosing X percentage probability on the probability distribution curve for value will tell you that it is $\mathrm{X}$ percentage probability that the value will end up below Allowable Cost. If you choose to set Allowable Cost at $25 \%$ probability, it will be $75 \%$ probability that the value is higher than Allowable Cost. The higher probability you want for achieving the value, the lower probability you should set for Allowable Cost. This also gives a higher contingency. 
Both NPRA and Statsbygg use steering targets for the project, and for the project management, set at a lower level than the cost limit (Allowable Cost). Target cost for the project manager is set at Expected Cost for Statsbygg and at P45 for NPRA. Target cost should be set at Allowable Cost or below (Zimina et al. 2012). When it comes to this aspect, the thinking in NPRA and Statsbygg is in line with the thinking in TVD. When the Allowable Cost is set, the design could start. For each design alternative, the Market Cost will be estimated and compared to Allowable Cost and the cost target.

Stochastic estimates could be applied to calculate Market Cost during the design stage in TVD. When Market Cost are estimated for a design solution, stochastic cost estimates could be applied. With the results of the estimate of Market Cost presented as a probability distribution, you are able to analyse the probability of Market Cost ending up below Allowable Cost, see Figure 3. When finishing the design phase, the probability of Market Cost ending up below Allowable Cost should be high, and the level of uncertainty, the standard deviation, should be low. When Allowable Cost is the absolute maximum amount of money available, the probability of ending up below Allowable Cost should be close to $100 \%$. Then the contingency also would be very high. If you choose to use Expected Market Cost when comparing to Allowable Cost, you have $50 \%$ probability of ending up below this number. Target Cost could be set at a lower level, for example at P45, like NPRA practice. This will give stretch target in order to drive innovation beyond current best practice (Pennanen and Ballard 2008). It is still important to steer to targets during construction.

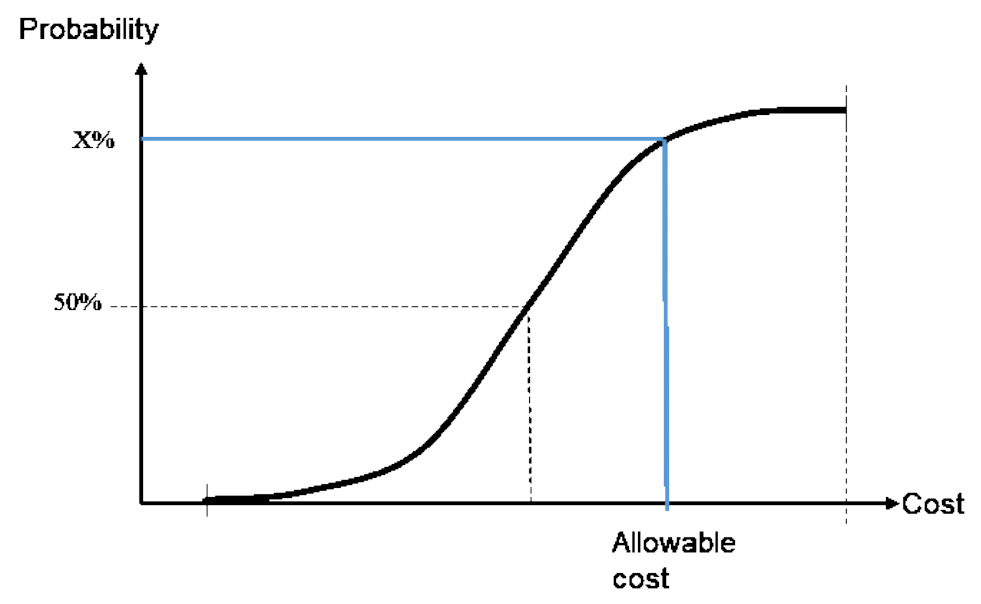

Figure 3. Market Most estimate represented by a probability distribution. Then probability of ending up below Allowable Cost could be found.

A refined framework for setting the targets based on stochastic estimates is proposed in table 1, based on the 9 steps of Pennanen and Ballard (2008). Table 1 include a description of how stochastic estimates could be applied in this framework. 
Table 1. Step by step process for setting targets based on stochastic estimates, based on the steps of Pennanen and Ballard (2008).

\begin{tabular}{|c|c|c|}
\hline ID & Step & Implication of Stochastic Estimates \\
\hline 1 & Assess the business case. & $\begin{array}{l}\text { Business case could include stochastic } \\
\text { estimate of Value }\end{array}$ \\
\hline 2 & $\begin{array}{l}\text { Determine stakeholder values } \\
\text { and define specifications of the } \\
\text { project }\end{array}$ & $\begin{array}{l}\text { Stakeholder values could be numbered by } \\
\text { stochastic estimates }\end{array}$ \\
\hline 3 & Determine the allowable cost & $\begin{array}{l}\text { Allowable Cost could be determined based on } \\
\text { a probability distribution of the total value of } \\
\text { the asset }\end{array}$ \\
\hline 4 & Determine the expected cost & $\begin{array}{l}\text { Expected cost will be output of the stochastic } \\
\text { estimate of Market Cost. Expected Cost will } \\
\text { be the } 50 \% \text { quantile, given a normal } \\
\text { distribution of the stochastic estimate }\end{array}$ \\
\hline 5 & $\begin{array}{l}\text { If expected cost is bigger than } \\
\text { the allowable cost then modify } \\
\text { the specifications }\end{array}$ & $\begin{array}{l}\text { When using probability distribution to } \\
\text { represent Market Cost, Expected Cost would } \\
\text { be the } 50 \% \text { quantile. When comparing with } \\
\text { Allowable Cost, you could consider a higher } \\
\text { quantile, like } 85 \% \text { quantile }\end{array}$ \\
\hline 6 & Go to Step 3 & \\
\hline 7 & $\begin{array}{l}\text { When expected cost is equal to } \\
\text { or less than the allowable cost, } \\
\text { start project delivery by setting } \\
\text { target cost equal to or below } \\
\text { expected cost }\end{array}$ & $\begin{array}{c}\text { Target Cost below Expected Cost will give } \\
\text { less probability than } 50 \% \text { to reach target, but } \\
\text { will at the same time drive innovation beyond } \\
\text { current best practice }\end{array}$ \\
\hline 8 & Launch design phase & $\begin{array}{c}\text { When estimating Market Cost for design } \\
\text { solutions, stochastic estimates could be } \\
\text { applied }\end{array}$ \\
\hline 9 & $\begin{array}{c}\text { Decompose product level target } \\
\text { cost to component level target } \\
\text { cost }\end{array}$ & $\begin{array}{l}\text { The component level target cost should be } \\
\text { defined on the chosen probability level }\end{array}$ \\
\hline
\end{tabular}

\section{CONCLUSION}

The purpose of this paper has been to discuss how stochastic estimates could be applied in TVD. A literature review on TVD together with a case study research on practice on stochastic cost estimates has been carried out.

Publications on Target Costing, Target Value Design and Target Value Design were studied to look into how cost targets are set in TVD. In TVD, Allowable Cost is set, based on the value the facility will provide the customer, or what the costumer is willing or able 
to pay. From the case studies, it is found that stochastic cost estimation methods are used both to estimate costs and to set cost targets. Both the cost limit and the steering goal are set by choosing probability level from a probability distribution of the total project cost.

From the analysis, it is found that stochastic estimates could be applied both to set Allowable Cost based on a probability distribution of the value, and to estimate the Market Cost in TVD based on a probability distribution of the Market Cost. When used to set Allowable Cost, either probability distribution of project costs prior to design or probability distribution of project value could be developed and used. It is a matter of choosing how high probability you want for getting higher value than Allowable Cost. Used to estimate the Market Cost, the probability distribution could be applied to analyse the probability of Market Cost ending up below Allowable Cost for the specific design alternative identified. It is important to remember that if choosing Expected Market Cost, you have $50 \%$ probability of ending up below Allowable Cost. To succeed with the project, it is essential not only to set realistic targets but also to steer the design and the construction to the targets.

Further research should be done to test the suggested approaches for applying stochastic cost estimation methods in TVD.

\section{REFERENCES}

Ballard G. 2006. "Rethinking Project Definition in terms of Target Costing", Proceedings IGLC-14, July 2006, Santiago, Chile.

Ballard G. 2007. "Target Costing in the Construction Industry". Presentaion in the P2SL 2007 Conference, Feb 2007. Berkeley, California.

Ballard G. 2008. "The Lean Project Delivery System: An Update". Lean Construction Journal, 2008.

Ballard, G., 2011. Target Value Design: Current Benchmark. Lean Construction Journal, pp. 79-84.

Ballard G. and Pennanen A., 2013. "Conceptual Estimation and Target Costing". Proceedings IGLC-21, July 2013, Fortaleza, Brazil.

Ballard, G. and Reiser P. 2002. - The St. Olaf College Fieldhouse Project: A Case Study in Designing to Target Costll. Proceedings of the 12th annual conference of the International Group for Lean Construction. Elsinor, Denmark.

Bowen, Glenn A. 2009. "Document analysis as a qualitative research method." Qualitative research journal 9.2 (2009): 27-40.

Cooper R. and Slagmulder R. 1997. "Target Costing and Value Engineering". Portland OR: Productivity Press.

Do, D., Ballard, G. and Tommelein I.D. 2015. "An Analysis of Potential Misalignment of Commercial Incentives in Integrated Project Delivery and Target Value Design.". In: Proc. 23rd Ann. Conf. of the Int'l. Group for Lean Construction. Perth, Australia, July 29-31, pp. 277-286, available at www.iglc.net.

Do. D., Chen C., Ballard G. and Tommelein I.D. 2014. "Target Value Delivery as a method for controlling project cost overruns". Proceedings International Group for Lean Construction. Oslo Norway. 
Feil P., Yook K.H. and Kim I.W. 2004. "Japanese Target Costing: A Historical Perspective". International Journal of Strategic Cost Management, 11.2.

Fellows, Richard F., and Anita MM Liu. 2015. Research methods for construction. John Wiley \& Sons, 2015

Flyvbjerg, B., Skamris Holm, M.S. og Buhl, S.L., 2002.Underestimation of Costs in Public Works Projects: Error or Lie? Journal of the American Planning Association, 68 (3), 279-295.

Klakegg, O.J. and Lichtenberg, S. 2016. "Successive Cost Estimation - Successful Budgeting of Major Projects". Procedia - Social and Behavioral Sciences. vol. 226.

Lichtenberg, S. 2000. "Proactive Management of Uncertainty-Using the Successive Principle". Lichtenberg \& Partners. Vedbæk, Denmark.

Lichtenberg S., 2016. " Successful control of Major Project Budgets". Administrative Sciences. vol. 6 (4).

Love P.E.D, Smith J., Simpson I, Regan M and Olatunji, O. 2015. "Understanding the landscape of overruns in Transport Infrastructure Projects". Environment and planning B: Planning and Design 2014, volume 41.

Morris, P.W.G. og Hough, G.H., 1987. "The Anatomy of Major Projects: A Study of the Reality of Project Management". New York: John Wiley and Sons.

Nguyen H.V., Tommelein I.D and Ballard G., 2008. "Process-based cost modelling to support Lean Project Delivery", Proceedings for the 16th Annual Conference of the International Group for Lean Construction. Manchester, United Kingdom.

Norwegian Ministry of Finance, 2008. "Cost Estimation (In Norwegian)". Norwegian Ministry of Finance, Oslo, Norway.

NPRA 2015. "Håndbok R764 Anslagsmetoden". Statens Vegvesen 2015, could be downloaded at www.vegvesen.no.

NPRA 2018. "Håndbok R760 Styring av prosjekter". Statens Vegvesen 2018, could be downloaded at www.vegvesen.no

NMF 2008, "Kostnadsestimering", Norwegian Ministry of Finance, Oslo, Norway.

KMD 2017. "Styring av store statlige byggeprosjekter i tidligfase", Guidelines, Norwegian Ministry of Local Government and Modernisation, Oslo, Norway.

Pennanen A., Ballard G. and Haahtela Y. 2010. "Design to targets in a target costing process". Proceedings IGLC-18, July 2010. Technion, Haifa, Israel.

Pennanen A., 2013. "Conceptual Estimation and Target Costing". Proceedings IGLC-21, July 2013. Fortaleza, Brazil

Pennanen A. and Ballard G. 2008. " Determining expected costs in the Target Costin Process". Proceedings for the 16th Annual Conference of the International Group for Lean Construction, Manchester, United Kingdom.

PMI 2011. "Practice Standard for Project Estimating". Project Management Institute. Newtown Square, USA.

Tanaka, M. (1989) "Cost planning and control systems in the design phase of a new product". Japanese management accounting, A world class approach to profit management. Productivity press, Massachusetts, USA, p 49-71

Tillmann P. A., Do Doanh; Ballard, G. (2017). "A case study on the success factors of Target Value Design." In LC3 2017 Volume II - Proceedings of the 25 th Annual 
Conference of the International Group for Lean Construction (IGLC), Walsh, K., Sacks, R., Brilakis, I (eds). Heraklion, Greece, pp. 563 - 570. DOI: https://doi.org/10.24928/2017/0324

Torp, O. and Klakegg, O.J. (2016) Challenges in Cost Estimation under Uncertainty - A Case Study of the Decommissioning of Barsebäck Nuclear Power Plant. Administrative Sciences. vol. 6 (4).

Welde M. (2017). "Cost Control in large public investments under the regime of external quality assurance", Concept research program, Norwegian University of Science and Technology, Trondheim, Norway.

Yin, Robert K. 2014. "Case study research: design and methods 5th ed." Thousand Oaks. Zimina D., Ballard G. and Pasquire C. 2012. "Target value design: using collaboration and a lean approach to reduce construction cost". Construction Management and Economics, 30:5, 383-398. DOI: 10.1080/01446193.2012.676658 